\title{
Molecular Addressability of Lipid Membrane Embedded Calixarenes towards Cytochrome C
}

\author{
Alexandra Poturnayova ${ }^{1,2}$, Michael Leitner ${ }^{3}$, Maja Snejdarkova ${ }^{2}$, Peter Hinterdorfer ${ }^{4}$, Tibor Hianik ${ }^{1}$ and Andreas Ebner $^{4 *}$ \\ ${ }^{1}$ Faculty of Mathematics, Physics and Informatics, Comenius University in Bratislava, Mlynska dolina, F1 Bratislava, 84248, Slovakia \\ ${ }^{2}$ Institute of Animal Biochemistry and Genetics, Slovak Academy of Sciences, 90028 Ivanka pri Dunaji, Slovakia \\ ${ }^{3}$ Center for Advanced Bioanalysis $\mathrm{GmbH}$, Gruberstrasse 40, 4020 Linz, Austria \\ ${ }^{4}$ Institute of Biophysics, Johannes Kepler University Linz, Gruberstrasse 40, 4020 Linz, Austria
}

\begin{abstract}
By means of the atomic force microscopy techniques we studied the surface topography of the supported bilayer lipid membranes (sBLM) composed of 1,2-sn-glycerodimyristoylfosfatidylcholine (DMPC) with incorporated calixarenes ${ }^{t} \mathrm{Oct}[6] \mathrm{CH}_{2} \mathrm{COOH}(\mathrm{CX})$ specific to cytochrome $\mathrm{c}$ (cyt c). It is supposed that cyt $\mathrm{c}$ interacts with $\mathrm{CX}$ through amino groups of lysine residues at its surface. Therefore we also applied single molecule force spectroscopy (SMFS) to analyze the mechanisms of interaction of cyt $\mathrm{c}$ with the $\mathrm{CX}$. In later case cyt $\mathrm{c}$ or individual $\mathrm{NH}_{2}$ group have been connected to the AFM tip through special linker. The topography of bare $s B L M$ in a gel state $\left(T=19^{\circ} \mathrm{C}\right)$ revealed relatively smooth surface $\left(R_{\mathrm{RMS}}=0.18 \mathrm{~nm}\right)$ and thickness $\sim 5.1 \mathrm{~nm}$ which agrees well with previous studies. Incorporation of CX into DMPC bilayer resulted in increase of the surface roughness $\left(R_{\mathrm{R} M \mathrm{~s}}=0.39 \mathrm{~nm}\right)$ and in increase of thickness in average by $0.5 \mathrm{~nm}$. The incubation of the layer with $30 \mathrm{nM}$ of cyt c resulted in a surface smoothing $\left(R_{\mathrm{RMS}}=0.32 \mathrm{~nm}\right)$ and in a further increase of the thickness between 0.7 to $1.2 \mathrm{~nm}$. The SMFS experiments with cyt c modified AFM tips approved its specific binding to $\mathrm{CX}$ and allowed us to determine the binding parameters $\mathrm{k}_{\text {off }}\left(1.14 \pm 0.59 \mathrm{~s}^{-1}\right)$ and $\mathrm{x}_{\beta}(3.98 \pm 0.63 \AA)$. SMFS experiments with an amino-ended linker also resulted in highly specific interactions with comparable values for $\mathrm{k}_{\text {off }}\left(2.74 \pm 0.66 \mathrm{~s}^{-1}\right)$ and $x_{\beta}(5.91 \pm 2.55 \AA)$. This suggests that both electrostatic and amino group specific interactions between cyt $c$ and CX cavity exist.
\end{abstract}

Keywords: Supported bilayer lipid membranes; Calixarene; Cytochrome c; AFM; Single molecule force spectroscopy; Molecular recognition

\section{Introduction}

Cytochrome c (cyt c), a small water soluble membrane hemeprotein found in the intermembrane space of mitochondria, is known to play a key role in physiological and pathological processes. Cyt $\mathrm{c}$ is a crucial regulator in the electron transport in mitochondrial respiratory chain and is also connected to apoptosis which is initiated by release of cyt c from mitochondria into the cytosol [1-5]. Cyt $c$ has the ability for membrane-induced formation of amyloid fibers [6-8]. The storage of cyt $\mathrm{c}$ in mitochondria is closely related to the special lipid cardiolipin (CL) that is found nearly only in the inner lipid membrane of mitochondria [9]. The interaction of CL with cyt $\mathrm{c}$ is expected to be based on electrostatic interaction between the polycationic cyt $\mathrm{c}$ and the anionic CL.

These mitochondrial lipid bilayers are known to bind cyt c effectively but have rather complex structure consisting of numerous lipid components onto which the integrated proteins are incorporated and peripheral proteins, like cyt $\mathrm{c}$ are embedded at membrane surface. There, the zwiterionic glycerophospholipids are the most common compounds of the membrane. For modeling the lipid bilayer and for simplification of the system (e.g. for artificial cyt c based sensors) the limitation to one kind of glycerophospholipids is beneficial. Among them 1,2-sn-glycero-dimyristoylphosphatidylcholine (DMPC) is very convenient. DMPC has main transition temperature at $\mathrm{T}_{\mathrm{M}}=23.9^{\circ} \mathrm{C}$. Below the transition temperature DMPC bilayer is in a gel phase whereas above this temperature it is in the fluid phase. Artificial functional lipid membranes can easily be generated by embedding membrane proteins and/or other membrane molecules allowing monitoring their behavior.

Calixarenes, cyclic oligomers based on a hydroxyalkylation product of a phenol and an aldehyde, are here of substantial interest [10-13] since they are known to bind cations, anions, nucleic acids, amino acids, catecholamines and other proteins highly specific [14]. An important example of such calixarenes is the calix[6] arene carboxylic acid derivative ( $\left.{ }^{\mathrm{t}} \mathrm{Oct}[6] \mathrm{CH}_{2} \mathrm{COOH}\right)$. It shows high extractability for cyt $\mathrm{c}$ and also interacts strongly with the $\mathrm{NH}_{3}^{+}$group of lysine $[15,16]$. There are many reports related to metal ion recognition with the calixarenes [17-19], but lesser works have been focused on the molecular recognition of proteins by calixarenes. In our recent work we showed that ( $\left.{ }^{\mathrm{t} O c t}[6] \mathrm{CH}_{2} \mathrm{COOH}\right)$ calixarene $(\mathrm{CX})$ can be incorporated into the supported bilayer lipid membrane (sBLM) where it can serve as receptor for impedimetric detection of cyt $\mathrm{c}$ with limit of detection of 10 $\mathrm{nM}[20]$. We investigated the interaction of cyt $\mathrm{c}$ with CX incorporated into the large unilamellar vesicles (LUV) composed of DMPC or into sBLM and compared this with not specific adsorption of cyt $c$ to the LUV containing DMPC and anionic phosphatidic acid (PA) or sBLM composed of a mixture of DMPC and dimyristoylphosphatidic acid (DMPA). We showed that with increasing concentration of CX the average size of LUV increased and zeta potential become more negative as it is suggested from dynamic light scattering experiments. For PA containing LUV the increase in vesicle diameter was less expressed, but zeta potential decreased similarly like that of LUV contained CX. Cyt

*Corresponding author: Andreas Ebner, Institute of Biophysics, Johannes Kepler University Linz, Gruberstrasse 40, 4020 Linz, Austria, Tel: +43 7322468 7637; Fax: +43732 2468 7633; E-mail: andreas.ebner@jku.at

Received April 02, 2014; Accepted May 15, 2014; Published May 20, 2014

Citation: Poturnayova A, Leitner M, Snejdarkova M, Hinterdorfer P, Hianik T, et al. (2014) Molecular Addressability of Lipid Membrane Embedded Calixarenes towards Cytochrome C. J Nanomed Nanotechnol 5: 202. doi:10.4172/21577439.1000202

Copyright: (C 2014 Poturnayova A, et al. This is an open-access article distributed under the terms of the Creative Commons Attribution License, which permits unrestricted use, distribution, and reproduction in any medium, provided the original author and source are credited. 
c did not affect significantly the LUV size, but reduced the negative zeta potential both for CX and PA containing vesicles. The analysis of binding process suggests that the main driving force for interaction of cyt $\mathrm{c}$ with CX incorporated in lipid bilayer is the electrostatic attraction of the positively charged cyt $\mathrm{c}$ molecules by the negative surface charge caused by CXs [21]. However, so far the topography of CX in a lipid bilayer and the molecular interaction forces between cyt $\mathrm{c}$ and CX have not been determined.

To overcome this gap of knowledge atomic force microscopy (AFM) seems to be the perfect candidate. On the one hand AFM has been proven to be a very useful tool in studying the surface topography of model lipid membranes [22-28] with high resolution and under near physiological conditions $[29,30]$. On the other hand the upgrade of the AFM tip to a mono-molecular biosensor allows to directly investigate the energy landscape of the molecular interaction. Using the AFM tip modified by certain ligand a complex rupture force with a surfacebound receptor can be measured at a single molecule level [31-35]. Ligands have been usually covalently coupled to the tip via long flexible spacer [36-39]. This linkage method allowing free movement and orientation of the ligand favors the complex formation with a receptor. The characteristic stretching of the spacer [40], preceding complex dissociation, allows us to better discriminate specific binding events from nonspecific adhesion. This is especially important for the study of low-affinity interactions between biomolecules.

In this work we applied gentle physiological AFM imaging to study the topography of lipid bilayers with incorporated CX and cyt $\mathrm{c}$ as well as single molecule force spectroscopy to analyze the binding between cyt c immobilized at AFM tip and CX incorporated into the lipid film.

\section{Materials and Methods}

\section{Materials}

All chemicals were of the highest purity commercially available:

37,38,39,40,41,42-hexakis(carboxymetoxy)-5,11,17,23,29,35hexakis(1,1,3,3,-tetra-metylbutyl) calix[6]aren ( ${ }^{\mathrm{t} O c t}[6] \mathrm{CH}_{2} \mathrm{COOH}$, $C X)$ was a gift by Dr. T. Oshima (University Miyazaki, Japan). 1,2-snglycero-dimyristoylfosfatidylcholine $(D M P C)$ was purchased from Avanti Polar Lipids Inc. (USA). Cytochrome $c$ from bovine hearth (cyt c), phosphate buffer saline tablet (PBS), HEPES, chloroform, ethanol, triethylamine (TEA), amino-propyltriethoxysilane (APTES), Neutravidin, and d-biotin were from Sigma Aldrich (Germany). The heterobifunctional crosslinkers NHS-PEG-biotin [41] and NHS-PEGActeal [42] were synthesized in house as described earlier. Biotin- $\mathrm{T}_{15}{ }^{-}$ $\mathrm{NH}_{2}$ was purchased from Thermo-Fisher Scientific GmbH (Germany). The buffers used were of following composition: PBS buffer: $2 \mathrm{mM}$ $\mathrm{KH}_{2} \mathrm{PO}_{4}, 10 \mathrm{mM} \mathrm{Na} \mathrm{HPO}_{4} .2 \mathrm{H}_{2} \mathrm{O}, 137 \mathrm{mM} \mathrm{NaCl}, 2.7 \mathrm{mM} \mathrm{KCl}$ at $\mathrm{pH}$ 7.4, HEPES buffer: $10 \mathrm{mM}$ HEPES, $150 \mathrm{mM} \mathrm{NaCl}, 20 \mathrm{mM} \mathrm{MgCl}, \mathrm{pH}$ 7.4 .

\section{Preparation of liposomes from DMPC}

The liposomes were prepared according to bath sonication method developed by Johnson et al. [43] which is widely used also in recent to studies [44] with modest modification. First, small amount of DMPC (2 $\mathrm{mg}$ ) has been added in a glass vessel and dissolved in $1 \mathrm{ml}$ of chloroform. The chloroform was evaporated using a continuous nitrogen gas stream by rotating the vessel. The flask with the evaporated film was inserted into a water bath having a constant temperature of $50^{\circ} \mathrm{C}$ for $60 \mathrm{~min}$. Again the vessel was floated with nitrogen gas for $10 \mathrm{~min}$. Afterwards $10 \mathrm{mM}$ HEPES buffer with $150 \mathrm{mM} \mathrm{NaCl}, 20 \mathrm{mM} \mathrm{MgCl}_{2}, \mathrm{pH}$ of 7.4 was added to achieve a final concentration of $0.5 \mathrm{mM}$ DMPC in a buffer. To obtain small unilamellar liposomes, the suspension was sonicated in a bath type sonicator DT-31 (Bandelin Electronic, Germany) 20 times during $30 \mathrm{sec}$ at $35-40^{\circ} \mathrm{C}$ until the solution was clear. For spreading the liposomes to a cleaved mica surface $100 \mu \mathrm{L}$ of the solution were applied with a deposition time of 35-40 min. Finally, the sample was washed thoroughly three times with PBS buffer. Similar method has been used for preparation of liposomes containing CX. In this case a mixture of DMPC and CX dissolved in chloroform in a molar ratio of 10:1 was prepared. After the formation of lipid bilayer without or with CX the cyt $\mathrm{c}$ dissolved in a PBS (concentration $30 \mathrm{nM}$ ) has been added in a small volume $(100 \mu \mathrm{l})$ that spreaded over the sample surface, after an incubation lasting 30 minutes the surface was gently washed with PBS.

\section{Physiological AFM imaging}

All AFM measurements were performed in PBS buffer using an Agilent 5500 AFM (Agilent Technologies, USA). All AFM imaging measurements were carried out in magnetically actuated tapping mode (MACMode, Agilent, USA) to ensure lowest possible indentation force on the investigated surface. Thus, magnetically coated silicon nitride AFM cantilevers (Type VII MACLevers, length: $125 \mu \mathrm{m}$, width: $35 \mu \mathrm{m}$, resonance frequency in water $18 \mathrm{kHz}$, nominal spring constant: 0.14 $\mathrm{N} / \mathrm{m}$, Agilent Technologies, USA) were used for MAC mode imaging of the DMPC layer. For all images 512 data points per line were set. The scan area of imaging was varied from $10 \times 10$ to $1 \times 1 \mu \mathrm{m}$. A temperature controller Model 331 (Lakeshore Cryotronics, USA) including a current booster N9656A (Agilent, USA) was used for adjusting and controlling a definite temperature with a peltier element was placed below the support.

Images of DMPC on mica with and without CX before and after addition of cyt $\mathrm{c}$ were acquired at $19^{\circ} \mathrm{C}$, i.e. when the lipid bilayer was in gel state, and at $32^{\circ} \mathrm{C}$, when the lipid layer was in liquid phase. Image processing, cross section analysis and statistical evaluation of the images were done using Gwyddion software (Gwyddion 2.34; http:// gwyddion.net).

\section{Tip functionalization}

The upgrade of inert siliconnitride tips of commercially available AFM cantilevers (MSCT, Bruker) for single molecule recognition force spectroscopy experiments was done in a multi-step procedure. For tethering both, cytochrome $\mathrm{c}$ as well as amino-functionalized $\mathrm{T}_{15}$ DNA, the first step was to generate amino-groups on the inert tip material. For this, the cantilevers were cleaned in ethanol (3 times) and chloroform ( 3 times) followed by gas phase deposition of APTES as described earlier [45]: two trays, one filled with $60 \mu \mathrm{L}$ freshly distilled APTES, the other one filled $20 \mu \mathrm{L}$ triethylamine (TEA) as catalyst, were placed in a 51 Argon flooded desiccator containing the tips for coating and allowed to react for 120 minutes. Afterwards APTES and TEA were removed, the desiccator was rinsed extensively with argon gas and the tips stayed there for 2 days for curing at room temperature. Afterwards, the tips used for coupling cytochrome $\mathrm{c}$ were functionalized with NHS-PEG-Acetal $(2 \mathrm{mg} / \mathrm{mL}$ in chloroform containing $0.5 \mathrm{vol} \%$ TEA as catalyst, $120 \mathrm{~min}$. reaction time) following the protocol of Wildling et al. [42]. Directly before incubation with cyt $c$ the acetal function was deprotected by immersion in citric acid $(10 \mathrm{~min})$ resulting in amino-reactive aldehyde residues on the outer end of the tip bound poly(ethyleneglycol) linker. Finally the coupling of cyt $\mathrm{c}$ was performed by immersing the aldehyde-tips in a PBS buffered solution containing $0.2 \mathrm{mg} / \mathrm{mL}$ cyt $\mathrm{c}$ for 120 minutes. These tips were washed in PBS and used immediately for force spectroscopy experiments. For coupling 

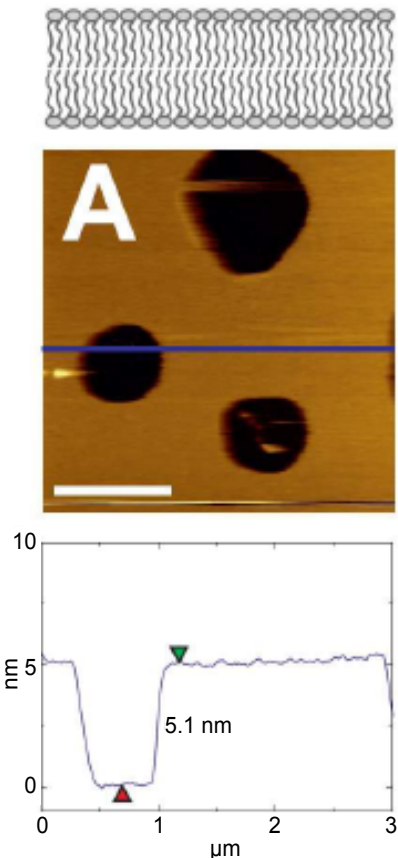
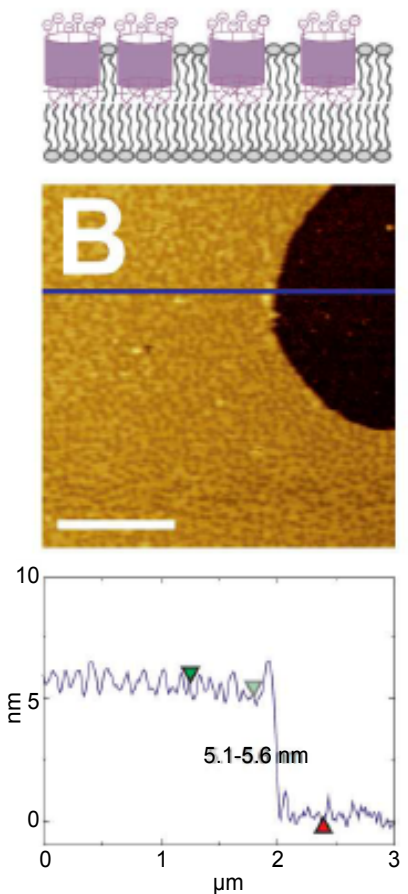
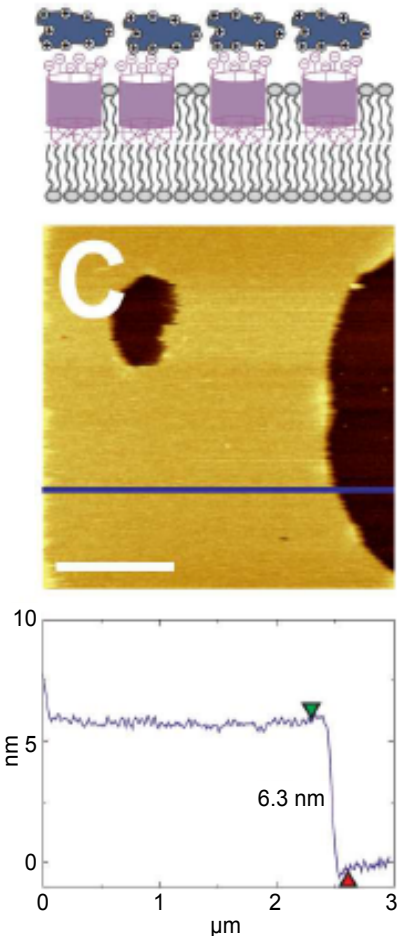

Figure 1: Topographical investigation of the DMPC self-assembled monolayer performing AFM imaging. (A) Bare DMPC bilayer on mica. The height difference between bilayer and mica is $0.5 \mathrm{~nm}$. The RMS of the surface roughness on the layer is $0.18 \mathrm{~nm}$. (B) DMPC layer with embedded Calix[6]arene molecules. Two phases are visible. The lower phases have a height of $5.1 \mathrm{~nm}$ whereas the higher areas have a height of $5.6 \mathrm{~nm}$. The RMS of the surface roughness on the layer is $0.49 \mathrm{~nm}$. (C) DMPC layer with embedded Calix[6]arene molecules after the addition of Cytochrome c. The height difference increased to $6.3 \mathrm{~nm}$ and the surface roughness had a RMS of $0.32 \mathrm{~nm}$ without detectable phase separation. $z$-Scale for all images is $12 \mathrm{~nm}$.

amino-functionalized $\mathrm{T}_{15}$ DNA-biotin to the APTES coated tips $1 \mathrm{mg}$ NHS-PEG-biotin was dissolved in $0.5 \mathrm{~mL}$ chloroform and $0.5 \%(\mathrm{v} / \mathrm{v})$ TEA were added. The APTES tips were immersed in this solution for 120 minutes and carefully rinsed in $\mathrm{CHCl}_{3}$. After drying in a gently stream of argon gas the biotinylated tips were placed into a solution of $0.1 \mathrm{mg} / \mathrm{mL}$ neutravidin in PBS and allowed to react for 60 minutes. These tips were then carefully rinsed with PBS to remove unbound neutravidin. Finally the biotinylated $\mathrm{T}_{15}$ DNA (containing an amino residue on the other end) was allowed to react overnight followed by careful rinsing with PBS buffer. All washing steps were performed three times for five minutes each. Also these tips were used immediately afterwards for force spectroscopy experiments.

\section{Force spectroscopy}

Single molecule force spectroscopy experiments were carried out with bio-functionalized tips (see chapter 2.4.) in PBS buffer. At each pulling velocity at least $1000-5000$ force distance cycles were performed. Typically after 250 force distance cycles (FDCs) the position on the support was changed to minimize position dependent artefacts. The measured deflection at the moment of rupture was translated into an unbinding force by multiplying the deflection with the spring constant. The spring constant itself was determined using the thermal noise method [46]. At each pulling force, all FDCs yielded in a typically 100-1000 unbinding forces distributed over a certain force range. To calculate the most probable rupture force out of these data, a probability density function [47] was drawn. In contrast to histograms data are weighted by their reliability and thus yield in a better resolution.

\section{Results and Discussion}

The small protein cytochrome $\mathrm{c}$ is important for both, physiological processes as well as artificial biosensing applications. This protein is released from inner membranes of mitochondria at cell apoptosis. Therefore its detection is important for diagnostics. For example, electrochemical biosensor based on calixarenes incorporated into sBLMs for cyt $\mathrm{c}$ detection has been reported by Mohsin et al. [20]. However, the mechanisms of interaction of cyt $\mathrm{c}$ with the calixarenes have not been studied yet in sufficient detail. It is assumed, that cyt $c$ interacts specific with the calixarene ${ }^{\mathrm{t}} \mathrm{Oct}[6] \mathrm{CH}_{2} \mathrm{COOH}(\mathrm{CX})$ through amino groups of lysine residues at the surface of cyt $\mathrm{c}$. The amino group is incorporated into the CX cavity. In addition negatively charged carboxyl groups at upper ring of the CX facilitate the electrostatic interaction with positively charged CX. Within this study we reveal the interaction properties of cyt $c$ with a powerful synthetic anchor, the calix[6]arene molecules embedded into a supported bilayer. For simplification we only used DMPC bilayers immobilized on freshly cleaved mica. Pure DMPC bilayers have a well-defined transition temperature from gel to fluid phase $\left(\mathrm{Tm}=23.9^{\circ} \mathrm{C}\right)$ [48]. All further measurements shown in this publication were performed below this temperature at $19^{\circ} \mathrm{C}$ adjusted with accurate temperature control equipment based on a Pelletier element embedded into the AFM liquid cell with an accuracy of $\pm 0.1^{\circ} \mathrm{C}$. Although dense layer can be formed easily we adjusted the incubation time and the vesicle concentration low enough ensuring to see both, the lipid bilayer as well as the bare mica allowing determining height changes directly by cross-section analysis. In a first part of this work we analyzed the surface topography 
roughness and determined the height profiles of lipid bilayers on mica surface without and with incorporated CX molecules as well as that with adsorbed cyt $c$. The second part was focused on measurement of forces between cyt $\mathrm{c}$ immobilised on AFM tip and the lipid bilayers at mica surface.

\section{Topography of the supported lipid membranes on the mica surface}

The results of AFM experiments focused on analysis of topography, roughness and height profile of supported lipid membranes are presented on Figure 1.

As shown in Figure 1A the formed bilayer (bright parts in the image) has a height of $\sim 5.1 \mathrm{~nm}$ with a surface roughness of $0.18 \mathrm{~nm}$ (rms) relative to the bare mica surfaces (dark parts at the image). This is consistent with values reported in the literature of $\sim 4.8 \mathrm{~nm}$ $[44,49,50]$. This result approves that the lipid film has the expected bilayer configuration. Thanks to negative surface charge of freshly cleaved mica the zwitterionic phosphatidyl groups of one monolayer of DMPC are in contact with the mica surface, while those of the outer monolayer are in contact with PBS. This allows directly comparing the effect of CX insertion. Liposomes to the above mentioned but with addition of embedded calix[6] arens (1:10 content) were prepared and incubated on freshly cleaved mica. Figure 1B shows the topography and cross sectional plot of a DMPC bilayer with incorporated CX. These layers are accompanied with sporadic defects. Here also the dark regions correspond to the bare mica surface (Figure 1B). On the AFM scan and especially in the corresponding cross-section two different heights of the lipid layer are observable. While the lower height nicely corresponds to the bare DMPC bilayer a second and $\sim 0.5 \mathrm{~nm}$ higher layer can be seen, most probable corresponding to an height increase introduced by the calix[6] arene molecules embedded into the lipid bilayer. Thanks to the negative charge of the carboxyl groups at upper ring of $\mathrm{CX}$ the electrostatic interaction with positively charged choline groups can affect the orientation of the zwiterionic dipoles which may cause rearrangement of the lipid bilayer structure [44,51]. Most probably the interaction of CX with phospholipids takes place at polar region of the bilayer. The results of our experiments on the study of the temperature phase behavior of liposomes containing CX using ultrasound spectroscopy method indicates that presence of $\mathrm{CX}$ does not affect the temperature of phase transition of phospholipids. This suggests that the hydrophobic part of bilayer is not significantly altered by calixarene molecules [52]. The analysis of the film roughness showed that the surface of DMPC-CX is significant rougher $\left(R_{R M S}\right.$ $=0.39 \mathrm{~nm})$ in comparison to DMPC $\left(\mathrm{R}_{\mathrm{RMS}}=0.18 \mathrm{~nm}\right)$. Finally, in addition to the topographical investigation the addressability of the embedded calixarens was proven by addition of cyt $c$ molecules on the formed DMPC-CX layer at a concentration of $30 \mathrm{nM}$. The effect of the formed complexes can be seen in Figure 1C. In comparison to the DMPC-CX surface without cyt c (Figure 1B) we did not observe two different heights on the lipid layer and thus a lower surface roughness $\left(\mathrm{R}_{\mathrm{RMS}}=0.32 \mathrm{~nm}\right)$. Nevertheless, a clear increase in height from $5.6 \mathrm{~nm}$ (or $5.1 \mathrm{~nm}$, respectively) to $6.3 \mathrm{~nm}$, corresponding 0.7 to $1.2 \mathrm{~nm}$, can be seen. Most probable this is caused by the coupling of cyt $c$ to the membrane embedded calixarenes since it is known that cyt $c$ interacts electrostatically with negatively charged carboxyl groups at upper ring of CX [15]. Measurements where cyt $c$ was incubated on CX-free DMPC bilayers did not show any height increase (data not shown), only on the edges of the pure DMPC layer to uncoated mica a height increase was observable. This suggestion is based on bright rim between mica and DMPC that are clearly visible at the image. These results suggest that cyt $c$ absorbs on the mica surface on the edge of DMPC and cause apparent thickening of the membrane. Cyt $\mathrm{c}$ is probably not able to penetrate into the DMPC lipid membrane due to the positively charged residues on the surface and interacts strongly with negatively charged support [53-55]. The height of bright rim was found 3.5-7 nm. The average dimension of the globular cyt $\mathrm{c}$ molecule has been reported as $3.4 \mathrm{~nm}$ [56], which is in good agreement with the height of bright rims on lipid bilayer, where cyt $\mathrm{c}$ is probably localized. After washing of DMPC-cyt c surface with PBS no significant changes were observed (image not shown).

To sum up, it is proven that calixarenes embedded into a DMPC lipid bilayer can act as anchor for cyt c. Most probably electrostatic interactions are responsible for this.

\section{Single molecule force spectroscopy analysis of the interaction between cytochrome $c$ and the supported lipid membranes with incorporated calixarenes}

For clarification the CX - cyt c interaction single molecule force spectroscopy (SMFS) [57] was used. SMFS allows measuring the interaction forces and dynamics of a ligand receptor pair at the real single molecule level [33,34,57-59]. For this, a single ligand molecule is tethered to the outer tip apex [39] whereas the corresponding ligand (or vice versa) is coupled to the surface (Figures 2A and 2B).

In so called force distance cycles (FDC) [57] the cantilever carrying the ligand functionalized tip is approached to the surface (Figure 2C, red line). No bending of the cantilever is observed until the tip touches the surface. Further approach results in an upwards bending, which is stopped when a previous set indentation force limit is reached. In the retraction part (Figure 2C, blue line) the cantilever gets removed from the surface resulting in a lowering of the bending. At the point of contact it reaches its resting position and stays there upon further retraction. In the contact time a receptor-ligand complex may be formed resulting in an additional (downwards) bending of the cantilever (Figure 2C, arrow) followed by a sudden rupture caused by dissociation of the complex. The maximum of the cantilever bending in the moment of complex rupture can be translated into a force according to Hook's law. The missing parameter, the cantilever spring constant, is measured for all SMFS data within this publication by using the thermal noise method [60]. At each given pulling velocity 1000-5000 FDCs have been performed and statistically analyzed. The most probable unbinding force was determined by construction a probability density function where the values are weighted by their reliability [47] as shown exemplary in Figure 3A. To gain insights into the energy landscape this rupture force was measured at different pulling velocities. Combining the Boltzmann ansatz with the stochastic description of the unbinding process according to Evans theory [61] allows revealing the energy landscape of the complex.

Within this study we explored the interaction of calix[6]arene and cyt $\mathrm{c}$ at the molecular level and compared it with the binding behavior of calix[6]arene with an isolated amine group. Thus, cyt $c$ and an isolated amine had to be bound to the outer tip apex of an APTES [45] coated cantilever. While cyt $\mathrm{c}$ was coupled directly via one of its lysins using the NHS-PEG-Acetal [42] linker (Figure 2A), the isolated amino group was generated on the tip in a multi-step procedure (Figure 2B). Thus, NHS-PEG-biotin [41] was coupled to the APTES tip resulting in a biotinylated surface followed by coupling of neutravidin (via the biotin binding pocket of the tetrameric neutravidin protein). Without sterical hindrance a second biotinylated molecule can be bound a binding site opposite to the first tether. Here the artificial DNA based 

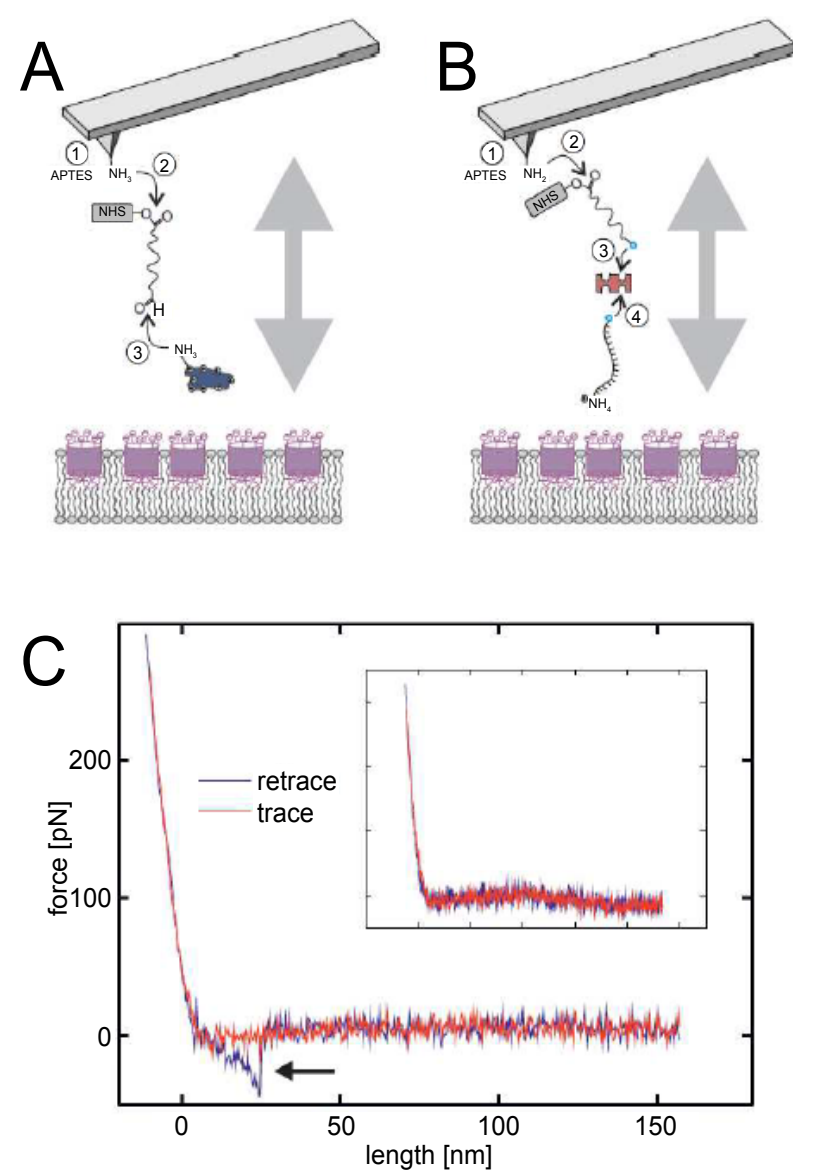

Figure 2: Single Molecule Force Spectroscopy. (A) Cytochrome c tip chemistry. Inert siliconnitride tips are reacted with APTES (1) resulting in reactive amino-groups on the surface. The heterobifunctional NHS-PEGAcetal (2) is coupled and deproteceted, resulting in an aldehyde residue on the outer PEG end. Finally the Cytochrome $c$ is covalently bound (3) via an amino-group of a lysine. (B) Poly- $\mathrm{T}_{-} \mathrm{NH}_{2}$ tip chemistry. Inert siliconnitride tips are reacted with APTES (1) resulting in reactive amino-groups on the surface. The heterobifunctional NHS-PEG-biotin (2) is bound covalently. (3) Neutravidin is coupled to the tip bound biotin via complex formation. Finally (4) another biotin-binding pocket is used to bind the biotin- $\mathrm{T}_{15}-\mathrm{NH}_{2}$ linker to the neutravidin functionalized tip. (C) Typical force distance cycle. The ligand functionalized cantilever is approached to the surface (red line) until a bending force limit is reached followed by a retraction period (blue line). In the case of a Cytochrome c - Calix [6] arene complex formation a downwards bending is observable followed by a sudden rupture of the complex (arrow). This effect is not observable when the same tip is used but no CX is present in DMPC bilayer (C, inset).

linker biotin-TTTTTTTTTTTTTTT-NH $\mathrm{N}_{2}$ was used resulting in an amino terminated distensible linker on the outer tip apex. As shown by Pincet et al. [62] the strength of a streptavidin-biotin complex incubated for a longer time period are significant higher compared to typical rupture forces in SMFS experiments allowing using the noncovalent neutravidin-biotin interaction within the linker structure. The pulling velocity in the SMFS experiments of the cyt $\mathrm{c}-\mathrm{CX}$ interaction was varied from $15-2000 \mathrm{~nm} / \mathrm{s}$ yielding values of the loading rate ranging from 80 to $20000 \mathrm{pN} / \mathrm{s}$ (Figure 3). It worth mentioning, that the phase of the DMPC lipid bilayer influences the measurements. At temperatures below TM the FDCs are similar to one illustrated in Figure 2C, whereas above this temperature the upper lipid layer gets partly pulled of and plateau-like structures (data not sown) appear in the FDCs in addition to the stretching of the PEG linker. Nevertheless, these lipid-layer induced artefacts did not influence the rupture forces and thus can be neglected. Anyhow, to be on the save side all FDCs showing this plateaus have been neglected for the data evaluation. The average binding probability was $17.6 \pm 6.7 \%$ whereby the lowest values were recorded at the highest pulling velocity (and vice versa) which can simply be explained by the lowered contact times and thereby lowered probability of complex formation.

Evaluation of the changes of the most probable unbinding force in dependence of the loading rate (Figure $3 \mathrm{~B}$ ) according to Evans theory resulted in kinetic off rate $\left(\mathrm{k}_{\mathrm{off}}\right)$ of $1.14 \pm 0.59 \mathrm{~s}^{-1}$ and $\mathrm{x}_{\beta}$ is $3.98 \pm 0.63$ $\AA$. Since only one slope is evident in Figure $3 \mathrm{~B}$ only a single barrier in the energy landscape can be assumed. Cytochrome $c$ is known to be highly positive charged since this small protein consists of 19 lysins (in case of bovine cyt c) within its amino-acid sequence. As a result of its

\section{A}

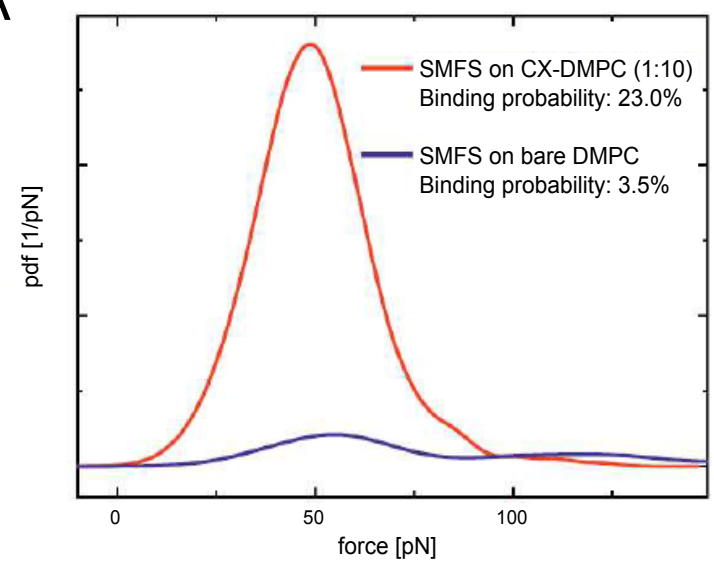

$\mathrm{B}$

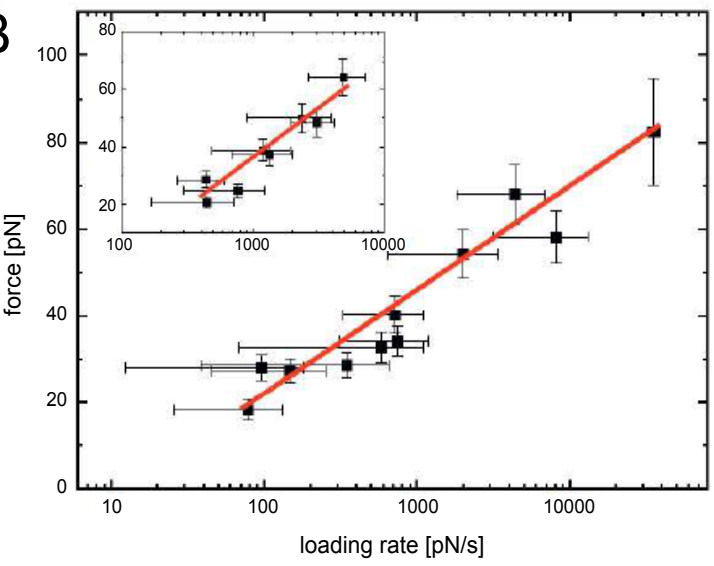

Figure 3: (A) Probability density functions. The red curve represents a typical pdf of the unbinding forces measured on a DMPC bilayer with embedded calix[6]arenes at constant pulling velocity $(600 \mathrm{~nm} / \mathrm{s})$. The binding probability was $23.0 \%$. The same experiment was repeated with the very same tip on a lipid bilayer consisting of pure DMPC (blue line). Here the probability dropped to $3.5 \%$ reflecting non-specific interactions. (B) Loading rate dependence of the unbinding force. Squares represent the most probable unbinding force at each pulling velocity (respectively at each loading rate). From the linear semi-logarithmical fit $\mathrm{x}_{\beta}$ and $\mathrm{k}_{\text {off }}$ are calculated according to Evans theory. The kinetic off rate for the cytochrome $c$ - Calix[6]arene complex is $1.14 \pm 0.59 \mathrm{~s}^{-1}$ and $x_{\beta}$ is $3.98 \pm 0.63 \AA$. The same measurements with a poly-T linker ended with a primary amine groups $\left(B\right.$, inset) result in a $k_{\text {off }}$ value of $2.74 \pm 0.66 \mathrm{~s}^{-1}$ and $x_{\beta}$ is $5.91 \pm 2.55 \AA$. 
Citation: Poturnayova A, Leitner M, Snejdarkova M, Hinterdorfer P, Hianik T, et al. (2014) Molecular Addressability of Lipid Membrane Embedded Calixarenes towards Cytochrome C. J Nanomed Nanotechnol 5: 202. doi:10.4172/2157-7439.1000202

Page 6 of 7

six carboxylic acid groups protruding out of the DMPC lipid bilayer membrane, the embedded calix[6]arene used in this study is highly negatively charged. Nevertheless the shown interaction does not give a direct proof that the amino residues of cyt $\mathrm{c}$ are the main driving force for complex formation. Thus, we performed SMFS experiments using the mono- $\mathrm{NH}_{2}$ linker biotin-TTTTTTTTTTTTTTT- $\mathrm{NH}_{2}$ on the same surface, on the DMPC bilayer with embedded calixarenes (ratio 1:10). Again by varying the pulling velocities the loading rate dependence of the unbinding force was measured and evaluated according to Evans theory. As a result (Figure $3 \mathrm{~B}$, inset) we calculated a $\mathrm{k}_{\text {off }}$ value of 2.74 $\pm 0.66 \mathrm{~s}^{-1}$ and $\mathrm{x}_{\beta}$ is $5.91 \pm 2.55 \AA$. Although the dissociation appears somewhat faster compared to cyt $\mathrm{cx}_{\beta}$ does not change significantly. The binding probability for these measurements was $23.7 \pm 11.9 \%$ which is even higher but not significant different compared to cytochrome $c$. All measurements were performed at $19^{\circ} \mathrm{C}$ in the gel-phase of DMPC. To proof the specificity of the interaction (i.e. to ensure that neither the DNA- $\mathrm{NH}_{2}$ nor cyt $\mathrm{c}$ interacts with the DMPC lipids itself instead of the embedded calixarens) the measurements were repeated using the same functionalized tips but on a pure DMPC bilayer. As shown in Figure 3A the binding probability (exemplary shown at a pulling velocity of 600 $\mathrm{nm} / \mathrm{s}$ ) is $23.0 \%$ (red line) for a DMPC bilayer surface with embedded calixarens, whereas it drops down to $3.5 \%$ when the surface is changed to pure DMPC. This proofs, that the measured interactions are highly specific.

\section{Conclusion}

In this study we investigated the formation of DMPC bilayers with embedded calix[6] arenes. It could be shown that the addition of calix[6] arenes (at a ratio of 1:10) caused their embedding into the outer lipid layer. Below the DMPC bilayer transition temperature (i.e. below $23.9^{\circ} \mathrm{C}$ ) two clearly separated height regimes are observable in the DMPC-CX sBLM, most probable corresponding to regions with and without embedded calixarenes. By adding cytochrome $\mathrm{c}$ to the formed layer the addressability of calix[6]arenes could be demonstrated indicated by a height increase of 0.7-1.2 nm. The specificity of the interaction, expected to be caused mainly by electrostatic adhesion was successfully proven by adding cyt $\mathrm{c}$ to pure DMPC resulting in no height increase. In general it was shown that mica covered with lipid bilayer and that modified by CX is a useful tool for mimicking and anchoring receptors of biomembranes. The properties of these surfaces were studied by near physiological AFM imaging and by atomic force spectroscopy methods. SMFS experiments with cyt c modified tips clearly demonstrated the addressability and allowed to determine $\mathrm{k}_{\text {off }}$ $\left(1.14 \pm 0.59 \mathrm{~s}^{-1}\right)$ and $\mathrm{x}_{\beta}(3.98 \pm 0.63 \AA)$. To prove the assumption that this interaction is based on electrostatic interaction SMFS experiments on calixarenes embedded in DMPC bilayers using an amino-ended linker were performed and resulted again in highly specific interactions with comparable values for $\mathrm{k}_{\text {off }}\left(2.74 \pm 0.66 \mathrm{~s}^{-1}\right)$ and $\mathrm{x}_{\beta}(5.91 \pm 2.55 \AA)$. Thus, it could be demonstrated that calixarenes are perfect candidates for immobilization of highly positively charged proteins like calixarene and that this anchoring process is mainly based on electrostatic interactions. These findings are expected to play an important role in the generation and use of surface based (e.g. electrochemical) biosensors.

\section{Acknowledgement}

We thank to Slovak Research and Development Agency (contracts No. APVV0410-10, SK-AT- 0009-12), VEGA (project No. 1/0785/12), COST TD 1003 and the BMWF Austria (Aktion Oesterreich-Slowakei Scholarship and WTZ, SK 05/2013) for financial support. We are grateful to Prof. Oshima from the University Miyazaki, Japan for gifting the calix[6]arenes used in this study. All authors declare no conflict of interest.

\section{References}

1. Jiang X, Wang X (2004) Cytochrome C-mediated apoptosis. Annu Rev Biochem 73: 87-106.

2. Kluck RM, Bossy-Wetzel E, Green DR, Newmeyer DD (1997) The release of cytochrome $\mathrm{c}$ from mitochondria: a primary site for $\mathrm{Bcl}-2$ regulation of apoptosis. Science 275: 1132-1136.

3. Liu X, Kim CN, Yang J, Jemmerson R, Wang X (1996) Induction of apoptotic program in cell-free extracts: requirement for dATP and cytochrome c. Cell 86 147-157.

4. Kagan VE, Bayir HA, Belikova NA, Kapralov O, Tyurina YY, et al. (2009) Cytochrome c/cardiolipin relations in mitochondria: a kiss of death. Free Radic Biol Med 46: 1439-1453.

5. Ow YP, Green DR, Hao Z, Mak TW (2008) Cytochrome c: functions beyond respiration. Nat Rev Mol Cell Biol 9: 532-542.

6. Kinnunen PK, Kõiv A, Lehtonen JY, Rytömaa M, Mustonen P (1994) Lipid dynamics and peripheral interactions of proteins with membrane surfaces. Chem Phys Lipids 73: 181-207.

7. Alakoskela JM, Jutila A, Simonsen AC, Pirneskoski J, Pyhäjoki S, et al. (2006) Characteristics of fibers formed by cytochrome $c$ and induced by anionic phospholipids. Biochemistry 45: 13447-13453.

8. Kim HS, Lee JH, Lee JP, Kim EM, Chang KA, et al. (2002) Amyloid beta peptide induces cytochrome $C$ release from isolated mitochondria. Neuroreport 13: 1989-1993.

9. Schlame M (2008) Cardiolipin synthesis for the assembly of bacterial and mitochondrial membranes. J Lipid Res 49: 1607-1620.

10. Gutsche CD (2008) Calixarenes: an introduction, 10, Royal Society of Chemistry.

11. Böhmer V (1995) Calixarenes, macrocycles with (almost) unlimited possibilities Angewandte Chemie International Edition in English 34: 713-745.

12. Ikeda A, Shinkai S (1997) Novel Cavity Design Using Calix[n]arene Skeletons: Toward Molecular Recognition and Metal Binding. Chem Rev 97: 1713-1734.

13. Steed JW, Atwood JL (2009) Supramolecular chemistry. (2ndedn), John Wiley \& Sons.

14. Blanda MT (2007) Calixarenes in the Nanoworld Edited by Jacques Vicens (ECPM-ULP-CERNS, Strasbourg, France) and Jack Harrowfield (ISIS-ULP CERNS, Strasbourg, France. Assistant Editor: Lassaad Baklouti (FSB, Bizerte, Tunisia). Springer: Dordrecht. Journal of the American Chemical Society 129 6963-6964.

15. Oshima T, Goto M, Furusaki S (2002) Extraction behavior of amino acids by calix [6] arene carboxylic acid derivatives. Journal of inclusion phenomena and macrocyclic chemistry 43: 77-86.

16. Oshima T, Suetsugu A, Baba Y, Shikaze Y, Ohto K, et al. (2008) Liquid membrane transport of cytochrome $c$ using a calix [6] arene carboxylic acid derivative as a carrier. Journal of Membrane Science 307: 284-291.

17. Delmau LH, Simon N, Dozol JF, Eymard S, Tournois B, et al. (1998) 'CMPOsubstituted'calix [4] arenes, extractants with selectivity among trivalent lanthanides and between trivalent actinides and lanthanides. Chemical Communications 1627- 1628.

18. Oshima T, Kakoi T, Kubota F, Ohto K, Goto M, et al. (1998) Rare earth meta extraction by liquid surfactant membranes containing a calixarene carboxylate derivative: permeation acceleration effect of sodium ions. Separation science and technology 33: 1905-1917.

19. Kakoi, T, Oshima T, Nishiyori T, Kubota F, Goto M, et al. (1998) Effect of sodium ions on the extraction of rare earth metals by liquid surfactant membranes containing a calix [4] arene carboxyl derivative. Journal of Membrane Science 143: 125-135.

20. Mohsin MA, Banica FG, Oshima T, Hianik T (2011) Electrochemical impedance spectroscopy for assessing the recognition of cytochrome $c$ by immobilized calixarenes. Electroanalysis 23: 1229-1235.

21. Garaiová Z, Mohsin MA, Vargová V, Banica FG, Hianik T (2012) Complexation of cytochrome $c$ with calixarenes incorporated into the lipid vesicles and supported membranes. Bioelectrochemistry 87: 220-225.

22. Giocondi MC, Yamamoto D, Lesniewska E, Milhiet PE, Ando T, et al. (2010) Surface topography of membrane domains. Biochim Biophys Acta 1798: 703718. 
Citation: Poturnayova A, Leitner M, Snejdarkova M, Hinterdorfer P, Hianik T, et al. (2014) Molecular Addressability of Lipid Membrane Embedded Calixarenes towards Cytochrome C. J Nanomed Nanotechnol 5: 202. doi:10.4172/2157-7439.1000202

23. Fritzen Garcia MB, Zoldan VC, Oliveira IRW, Soldi V, Pasa AA, et al. (2013) Peroxidase immobilized on phospholipid bilayers supported on au (111) by DTT self-assembled monolayers: Application to dopamine determination. Biotechnology and bioengineering 110: 374-382.

24. Attwood SJ, Choi Y, Leonenko Z (2013) Preparation of DOPC and DPPC Supported Planar Lipid Bilayers for Atomic Force Microscopy and Atomic Force Spectroscopy. Int J Mol Sci 14: 3514-3539.

25. Yilmaz N, Yamada T, Greimel P, Uchihashi T, Ando T, et al. (2013) Real-time visualization of assembling of a sphingomyelin-specific toxin on planar lipid membranes. Biophys J 105: 1397-1405

26. Heath GR, Johnson BR, Olmsted PD, Connell SD, Evans SD (2013) Actin assembly at model-supported lipid bilayers. Biophys J 105: 2355-2365.

27. Fotiadis D (2012) Atomic force microscopy for the study of membrane proteins. Curr Opin Biotechnol 23: 510-515.

28. Liu LN, Scheuring S (2013) Investigation of photosynthetic membrane structure using atomic force microscopy. Trends Plant Sci 18: 277-286.

29. Whited AM, Park PS (2014) Atomic force microscopy: a multifaceted tool to study membrane proteins and their interactions with ligands. Biochim Biophys Acta 1838: 56-68.

30. Picas L, Milhiet PE, Hernández-Borrell J (2012) Atomic force microscopy: a versatile tool to probe the physical and chemical properties of supported membranes at the nanoscale. Chem Phys Lipids 165: 845-860.

31. Rief M, Grubmüller H (2002) Force spectroscopy of single biomolecules. Chemphyschem 3: 255-261.

32. Lee GU, Chrisey LA, Colton RJ (1994) Direct measurement of the forces between complementary strands of DNA. Science 266: 771-773.

33. Florin EL, Moy VT, Gaub HE (1994) Adhesion forces between individual ligandreceptor pairs. Science 264: 415-417.

34. Moy VT, Florin EL, Gaub HE (1994) Intermolecular forces and energies between ligands and receptors. Science 266: 257-259.

35. Lo Ys, Huefner ND, Chan WS, Stevens F, Harris JM, et al. (1999) Specific interactions between biotin and avidin studied by atomic force microscopy using the Poisson statistical analysis method. Langmuir 15: 1373-1382.

36. Haselgrübler T, Amerstorfer A, Schindler H, Gruber HJ (1995) Synthesis and applications of a new poly(ethylene glycol) derivative for the crosslinking of amines with thiols. Bioconjug Chem 6: 242-248.

37. Hinterdorfer P, Baumgartner W, Gruber HJ, Schilcher K, Schindler H (1996) Detection and localization of individual antibody-antigen recognition events by atomic force microscopy. Proc Natl Acad Sci U S A 93: 3477-3481.

38. Hinterdorfer P, Kienberger F, Raab A, Gruber HJ, Baumgartner W, et al. (2000) Poly (Ethylene Glycol): An Ideal Spacer for Molecular Recognition Force Microscopy/Spectroscopy. Single Molecules 1: 99-103.

39. Ebner A, Wildling L, Zhu R, Rankl C, Haselgrübler T, et al. (2008) Functionalization of probe tips and supports for single-molecule recognition force microscopy. Top Curr Chem 285: 29-76.

40. Kienberger F, Pastushenko VP, Kada G, Gruber HJ, Riener C, et al. (2000) Static and Dynamical Properties of Single Poly(Ethylene Glycol) Molecules Investigated by Force Spectroscopy. Single Molecules 1: 123-128.

41. Riener CK, Stroh CM, Ebner A, Klampfl C, Gall AA, et al. (2003) Simple test system for single molecule recognition force microscopy. Analytica Chimica Acta 479: 59-75.

42. Wildling L, Ebner A, Kamruzzahan ASM, Hahn CD, Kienberger F, et al. (2005) Linking of underivatized antibody molecules to AFM tips via long, distensible poly(ethylene glycol) chains. Biophysical Journal 88: 154-155.

43. Johnson SM, Bangham AD, Hill MW, Korn ED (1971) Single bilayer liposomes. Biochim Biophys Acta 233: 820-826.

44. Garcia-Manyes S, Oncins G, Sanz F (2005) Effect of temperature on the nanomechanics of lipid bilayers studied by force spectroscopy. Biophys $\mathrm{J} 89$ : 4261-4274.

45. Ebner A, Hinterdorfer P, Gruber HJ (2007) Comparison of different aminofunctionalization strategies for attachment of single antibodies to AFM cantilevers. Ultramicroscopy 107: 922-927.
46. Butt $\mathrm{HJ}$, Jaschke $M$ (1995) Calculation of thermal noise in atomic force microscopy. Nanotechnology 6: 1-7.

47. Baumgartner W, Hinterdorfer P, Schindler H (2000) Data analysis of interaction forces measured with the atomic force microscope Ultramicroscopy 82: 85-95.

48. Mabrey S, Sturtevant JM (1976) Investigation of phase transitions of lipids and lipid mixtures by sensitivity differential scanning calorimetry. Proceedings of the National Academy of Sciences 73: 3862-3866.

49. Enders O, Ngezahayo A, Wiechmann M, Leisten F, Kolb HA (2004) Structural calorimetry of main transition of supported DMPC bilayers by temperaturecontrolled AFM. Biophys J 87: 2522-2531.

50. Tristram-Nagle S, Liu Y, Legleiter J, Nagle JF (2002) Structure of gel phase DMPC determined by X-ray diffraction. Biophys J 83: 3324-3335.

51. Mecke A, Lee DK, Ramamoorthy A, Orr BG, Holl MM (2005) Synthetic and natural polycationic polymer nanoparticles interact selectively with fluid-phase domains of DMPC lipid bilayers. Langmuir 21: 8588-8590.

52. Garaiová Z, Mohsin MA, Vargová V, Banica FG, Hianik T (2012) Complexation of cytochrome $c$ with calixarenes incorporated into the lipid vesicles and supported membranes. Bioelectrochemistry 87: 220-225.

53. Pinheiro TJ, Watts A (1994) Lipid specificity in the interaction of cytochrome c with anionic phospholipid bilayers revealed by solid-state 31P NMR. Biochemistry 33: 2451-2458.

54. Heimburg T, Marsh D (1995) Protein surface-distribution and protein-protein interactions in the binding of peripheral proteins to charged lipid membranes. Biophysical Journal 68: 536-546.

55. El Kirat K, Morandat S (2009) Cytochrome c interaction with neutral lipid membranes: influence of lipid packing and protein charges. Chem Phys Lipids 162: $17-24$.

56. Wilkins DK, Grimshaw SB, Receveur V, Dobson CM, Jones JA, et al. (1999) Hydrodynamic radii of native and denatured proteins measured by pulse field gradient NMR techniques. Biochemistry 38: 16424-16431.

57. Ebner A, Nevo R, Rankl C, Preiner J, Gruber H, et al. (2009) Probing the energy landscape of protein-binding reactions by dynamic force spectroscopy. In Handbook of single-molecule biophysics, Springer.

58. Hinterdorfer P, Dufrêne YF (2006) Detection and localization of single molecular recognition events using atomic force microscopy. Nat Methods 3: 347-355.

59. Grandbois M, Beyer M, Rief M, Clausen-Schaumann H, Gaub HE (1999) How strong is a covalent bond? Science 283: $1727-1730$.

60. Hutter JL, Bechhoefer J (1993) Calibration of atomic-force microscope tips. Review of Scientific Instruments 64: 1868-1873.

61. Merkel R, Nassoy P, Leung A, Ritchie K, Evans E (1999) Energy landscapes of receptor-ligand bonds explored with dynamic force spectroscopy. Nature 397 $50-53$

62. Pincet F, Husson J (2005) The solution to the streptavidin-biotin paradox: the influence of history on the strength of single molecular bonds. Biophys $\mathrm{J} 89$ : 4374-4381. 